\title{
Model of erosion-landslide interaction in the context of the reservoir water level variations (East Siberia, Russia): Factors, environment and mechanisms
}

\author{
Oksana Mazaeva, Viktoria KhaK* and Elena Kozyreva \\ Laboratory of Engineering Geology and Geoecology, Siberian Branch, Institute of the Earth's Crust \\ of Russian Academy of Sciences, Lermontov Street, 128, Irkutsk 664033, Russia. \\ *Corresponding author.e-mail: khak@crust.irk.ru
}

\begin{abstract}
A comprehensive investigation of landslide-erosion interactions has been carried out in the local shore geosystem of the Bykovo site located on the left shore of the Bratsk reservoir. The landslide process develops in the Mid-Quaternary grounds $\left(\mathrm{aQ}_{\mathrm{II}}^{3}\right)$ of the erosion-accumulative terrace's fragment that comprises sand, sand with pebbles, sandy loams and loams. This study aims to assess the environmental factors of interacting landslide and gully erosion processes, to estimate their temporal dynamics by comparative analysis of cartographic models based on the data of repeated theodolite surveys, and to find out what level regime of the reservoir stimulates the activation of the landslide process. The authors propose two-stage descriptive model of erosion-landslide interaction and development mechanisms in the context of the reservoir water level variations in the Bratsk reservoir. The activation of landslide processes in the reservoir shores follows the periods of high water level stands. Shore slope stability is disturbed by abrasion of slope foot and inundation of the slide zone. The soils subject to landslide, erosion-landslide and erosion processes differ in their microstructure and properties. Largest erosion susceptibility is typical of soils with skeleton-aggregated microstructure, fine- and coarse-silt sandy loams and loams of high porosity, whose interstructural bonds are attributed to water-soluble salts (Sws = $0.4-0.5 \%)$ and high carbonate contents $(\mathrm{Scr}=34-66 \%)$. High dispersion and aggregation of clay fractions is typical of the loams of the slide zone. The structure of soils subject to deformation slide is represented primarily by fine-sand particles and aggregates with smaller cohesion and strength properties.
\end{abstract}

\section{Introduction}

The relationships of the processes are of current concern in the context of modern geomorphology. Problems of the hillslope-to-channel coupling were described in a number of publications (Harvey 2001; Slattery et al. 2002; Schwab et al. 2008). All relief forms are affected by the relationships of processes and environmental factors. By 'coupling' we shall basically mean the system's characteristic that is largely responsible for its susceptibility (stability) and appears in the form of internal connectivity or linkage among component parts of the system (Brundsen and Thornes 1979). In terms of the coupling concept in the fluvial geomorphology (Harvey 2002), the mechanism of erosion-landslide interaction can be related to the hillslope-to-channel coupling in local scale.

Keywords. Landslide; gully erosion; interaction; local shore geosystem; soil microstructure. 
Erosion-landslide interaction belongs to a group of widely spread geomorphological phenomena. Most commonly, landslide is closely associated with the erosion processes (Lomtadze 1977). The origination of landslide on the shore slopes is induced by lateral erosion in the river banks, coastal erosion (Fiorillo 2003; Isika et al. 2004) or caused by reservoir inundation (Qi et al. 2006; Wang et al. 2008). The landslide and fluid soil creep cause the change in the gully head form and the lateral expansion of gullies (Zinck et al. 2001). Numerous cases of gully development within large-size landslide bodies are known. The areas of surface runoff and gully development tend to occur in depressions in the form of old landslide scars (Valentin et al. 2005). Only elementary knowledge of the relationships of these processes, their mechanisms and order of interaction is available; these problems for the case area are being discussed for the first time.

In Russia, comprehensive study of coastal processes was of vital importance in mid-20th century due to the large-scale construction of hydro-electric power stations in the European territory of Russia and in Siberia. Monitoring of the shore areas of reservoirs of the Angara cascade hydro power stations, including those of the Bratsk reservoir, started in 1962 before the reservoir filling.

The Bratsk reservoir is a large flatland water basin with seasonal and perennial level fluctuations (3-4 $\mathrm{m}$ and up to $10 \mathrm{~m}$, respectively). Creation of the Bratsk reservoir caused reactivation of numerous exogenic processes in the shore areas. The disturbance of coastal gullies caused the following changes: the drainage area reduced in size and form, the base level of erosion decreased in depth, and the shore edge was displaced due to the abrasion process (Khak and Kozyreva 2012).

The worldwide investigation of landslide phenomenon is very important due to their hazardous and eventually disastrous consequences; for example, the landslide processes can cause considerable harm to the engineering-geological environment, damage to industrial and municipal structures and to the areas of active land use; furthermore they can be the cause of substantial economical loss (Hervas 2003). Extensive landslide development in slopes and scarps is typical of the areas of intensive human activity.

The highest concentration of landslide was recorded on the territory of the Oka shore area of the Bratsk reservoir, particularly in the areas of terrigene deposits of Ordovician age, as well as in the Angara shores, which are composed of gypsumanhydrite rock deposits of Cambrian and clayey deposits of Ordovician age (Ovchinnikov et al. 1999). The landslide-affected areas are sparsely inhabited; therefore, the landslides in this territory are considered as those of medium (or rarely high) hazard. Nevertheless, they present a certain hazard to areas of land use and water protection zones.

The slide deformations of shore slopes are defined as shear slide and fluid soil creep. In 2007, the total area of slide-affected slope was recorded to have reached $4000 \mathrm{~m}^{2}$. According to the classification presented by Derek Cornforth in 'Landslides in Practice: Investigation and Remedial/preventive Options in Soils' (2005), the given landslide should be referred to the medium category given the extent of the deformation of the affected area.

Almost all inherited landslides (i.e., those developing in shore areas prior to the reservoir creation) were activized after the reservoir filling (Ovchinnikov et al. 1999). In some cases, the abrasion process was the primary factor of landslide origination. The permanent observations revealed that the landslide reactivation occurred with different intensities dependent on the level conditions in the reservoir. The main cause of the renewed activity of old landslides and origination of new ones in the shores of the Angara reservoirs is clayeyrock decrease in strength on flooding (Trzhtsinskii 1978). Further investigations of the landslide dynamics showed decrease of its activity during the period of low water in the reservoir (Ovchinnikov et al. 1999).

Investigations of the landslides on the Geheyan reservoir (Qi et al. 2006) and the Three Gorges reservoir ( $\mathrm{Li}$ et al. 2010) in China and Canelles reservoir in Spain (Pinyol et al. 2012) showed that landslide process is closely associated with water level variations. For example, the investigation of the Maoping Landslide in shores of the Geheyan reservoir in China (Qi et al. 2006) has revealed reactivation of this landslide process after filling of the reservoir. However, further observations showed that the shore deformation is due to the sharp drawdown rather than to the sharp rise of reservoir water level.

The difference in the mechanisms of landslide reactivation can be associated with morphometric and morphological characteristics of reservoirs, geologic-structural features of areas, and different position of slide zones relative to the reservoir water level.

Thus, it has been found that the filling of reservoirs stimulated the reactivation of old landslide processes and origination of new ones. The discrepancy between the concepts concerns the following question: what level regime stimulates activation of landslide process?

This study aims to assess the conditions, factors and environment of interacting processes and to analyze their temporal dynamics, estimate the short-term changes by comparative analysis of cartographic models based on the data of repeated theodolite survey and defining of the development 
mechanisms. The authors propose a descriptive model of erosion-landslide interaction in the context of the reservoir water level variations.

\section{Study area}

The case site is located in a forest-steppe region marked by total 300-400 $\mathrm{mm}$ annual precipitation amount, with irregular yearly distribution: the maximum $(>75 \%)$ in summer months $(25 \%$ being recorded in July-August). According to Wishmeer and Smith's rainfall erosivity index, the study area is characterized by a 2.5-5.0 index of erosional precipitation (Bazhenova et al. 1997).

The Bratsk reservoir is of energy-generating importance, with multi-year drainage regulation, with yearly level fluctuations in the range of $2-3 \mathrm{~m}$ and lowering up to $10 \mathrm{~m}$. The annual level fluctuation regime is marked by seasonal cyclic recurrence, with irregular water balance rates: the highest level in autumn and lowest level in spring. Cases of reservoir drawdown occur shortly after its inundation, i.e., the duration of definite level stand is short, lasting from several days to a month.

The aerial photos taken in 1953 (prior to the reservoir inundation) show that the slope was not affected by landslide. Since 1969 (after the reservoir filling), sand quarrying in the north of the area caused definite changes in environmental conditions. The deformations are likely to have been caused by the creation of the reservoir, sand quarrying, or their reciprocal influence. Our investigations were carried out on the abandoned quarry did not imply any influence of anthropogenic factors (such as sand quarrying) upon the geodynamical aspects. Here, the intense development of landslide and erosion was recorded.

A comprehensive investigation of the landslideerosion interaction was carried out in the local shore geosystem: the investigation sites are marked by paragenetic exogenic processes that reflect the state of the system and its temporal and spatial changes. We believe that the local shore geosystems are confined to the shore areas in the backwater influence zone (Mazaeva et al. 2006).

\section{Geologic settings}

The area of Bykovo was selected as a case site for the erosion-landslide interaction (figure 1) and studies were carried out in the NE-exposed slope of the Bratsk reservoir's shore area of 250$300 \mathrm{~m}$ length. The coast and abrasive scarp areas are composed of gypsum-saliferous-carbonate rock formations of Lower-Middle-Cambrian $\left(\epsilon_{1-2} l \mathrm{lt}\right)$, consisting of dolomites, limestones, gypsum, anhydrite and carbonate breccias. The bedrock outcrops occur in bench scarps of southern and northern parts of the studied site. In some places,

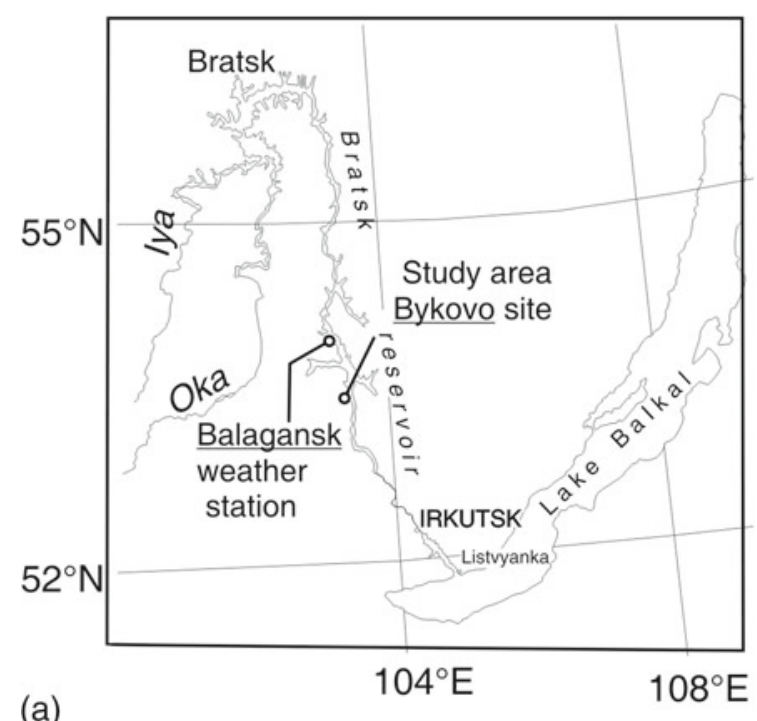

(a)
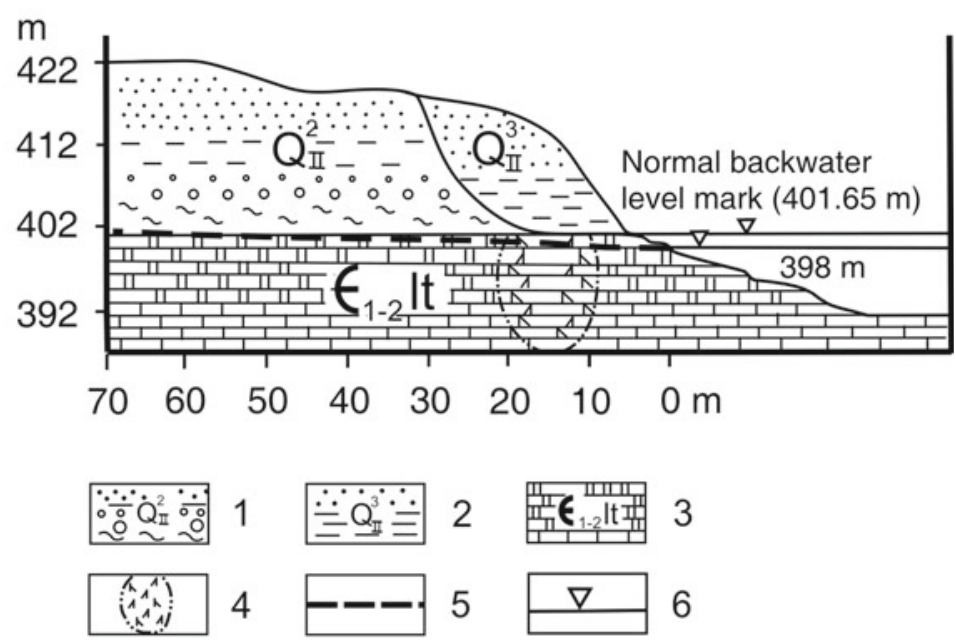

(b)

Figure 1. The map of investigation site: (a) location map of the Bykovo site; (b) geological cross section of the Bykovo site. (1) alluvium VI of the $\mathrm{aQ}_{\mathrm{II}}^{2}$ terrace: sandy loam and clays of brown colour with sand intercalations; (2) alluvium $\mathrm{V}$ of the $\mathrm{aQ}_{\mathrm{II}}^{3}$ terrace: the fine-grain sands with coarse gravel, and loam and sandy loam layers in the upper area; (3) the gypsum-saliferous-carbonate rock formations of Lower-Middle-Cambrian $\left(\in_{1-2}\right.$ lt), consisting of dolomites, limestones, gypsum, anhydrite and carbonate breccias; (4) supposed karst cavity filled with loose material; (5) ground water level; and (6) water level mark. 
the occurrence of the Middle-Upper-Cambrian deposits of the Verkholensk suite's Osa member $\left(\epsilon_{2-3} \mathrm{Vl}_{1}^{1}\right)$ was recorded; this member consists of marl, dolomite, argillites and aleurolite intercalations with thin gypsum lenses. The lower part of the suite is composed of clays with red and green breccias.

Geomorphological structure of the area is represented by IV, V and VI fragments of erosionalaccumulative terraces. The alluvium IV of the $\mathrm{aQ}_{\mathrm{II}}^{4}$ terrace consists of fine- and medium-grain sands of yellow and yellow-grey colour with intercalations of clays and sandy loam as well as 0.5 m-thick layers of coarse gravel in the base. The alluvium $\mathrm{V}$ of the $\mathrm{aQ}_{\mathrm{II}}^{3}$ terrace contains primarily fine-grain sands with coarse gravel with loam and sandy loam layers in the upper area. The alluvium VI of the $\mathrm{aQ}_{\mathrm{II}}^{2}$ terrace consists mainly of sandy loam and clays of brown colour with sand intercalations.

The landslide process develops in the MidQuaternary grounds (aQ $\mathrm{II}$ ) of the erosionaccumulative terrace's fragment that consists of sand, sand with pebbles, sandy loams and loams. The reservoir inundation caused the variations of groundwater level, abundant humidification of sands, sand dust, and loams, which led to slope deformation due to landslide.

The field investigations revealed that the modern relief of the area is the consequence of landslide and erosion processes; here landslides, ancient gullies and active erosion forms are observed. The quarry wall edges were affected by erosion forms, whose upper parts developed due to suffosionsubsidence processes. The old ravine is marked by a subdued shape, grass-covered slopes and a bushy thalweg area. Modern erosion forms in the slide slopes develop as inherited along the runoff scours in the upper parts of the emerge slope. In southern and northern parts of the area, a series of wave-cut notches in karstic rocks decrease the slope stability.

The karst process is affected by anthropogenic impact (fluctuation of the reservoir water level); its development is confined to the axes of regional jointing and lithological fissuring planes. The subsurface karst caves, caverns and fractures are the reasons of high water permeability of the slope massif. As it has been stated by geophysical mapping, the karst caves filled with loose material and situated in the aeration zone were subject to alternating inundation and dewatering due to fluctuations of reservoir water level. During the long period of reservoir operation, the characteristics of clayey material considerably changed; laboratory analyses showed low mechanical strength; the inundation increased its plasticity and fluidity. The presence of montmorillonite minerals in the clay fractions leads to swelling of clayey material.
The presence of clay material in the contact area of bedrocks and Quaternary deposits promotes sliding of overlying rocks. In the Priangaria area, numerous cases of landslide block formation were recorded as the soil blocks slid slowly over the clay layer (Palshin 1968; Trzhtsinsky et al. 2003).

\section{Methodology}

The paper analyzes the regional geosystems with all inherent interactions, as well as special method of estimation of geodynamical conditions were used with reference to the Bratsk reservoir (Mazaeva et al. 2006); a wide scope of materials ranging from the reservoir design to its actual exploitation were used.

An important aspect in the study of process interactions is the 'geosystem approach' (Krut 1973; Yudin 1978; Bondarik 1981). In terms of this strategy, geological processes can be considered as "a form of movement, development of nearsurface geosystem in physical time, in the context of the interaction with external environments, or the interaction of geosystem elements" (Bondarik 1981 , p. 203). The system object manifests itself primarily via its coupling and typology. This paper shows the actual approach to the study of complex and multi-factor geosystems in the context of interaction of processes (landslide, erosion and abrasion), rather than the study of particular processes.

The investigation strategy is based on three stages: (1) determination of key sites by accumulation and study of materials on the behaviour and activation of geological processes in the reservoir influence areas in different periods; analysis of conditions and factors of subsystems development prior to and after the reservoir creation, as well as interpretation of aerial photos; (2) setting up special systems for monitoring and geodetictopographical survey; and (3) analysis of the obtained data and creation of 3-dimensional cartographic models of the relief, and determining of qualitative and quantitative interactions in the geosystem. The comparative analysis of the dynamics of the process inherent elements in the background of natural and anthropogenic factors determines the relationship of the system elements.

\subsection{The geodetic-topographical survey}

A geodetic-topographical survey was carried out as part of the study of the Bykovo site: the T-30 theodolite and tacheometric methodology was used for this purpose. A system of six benchmarks was set-up on the landslide-affected slope; two hanging 
benchmarks were also allocated in the coast zone. The benchmarks were coupled with each other for horizontal angle measurement. For the landslide processes survey, the landslide scar brows, the rear joint, and foot of the landslide slope were drawn. The tacheometric ravine survey was hindered by erosion-suffosional processes in the quarry wall edges; therefore, the density of measuring points in these places was increased. The surveys were carried out in the summer months of 2003-2007.

\subsection{Comprehensive study of soils}

To study the environmental conditions for developing and interacting geological processes, a comprehensive analysis of soil was carried out. For this purpose, the soil samples were taken in the Bykovo site by trenching and stripping of slopes not affected by landslide, in the sliding zone, and in the areas of natural erosion from exposure in landslide body and its slopes.

In the Analytical Centre of the Institute of the Earth's Crust, the following characteristics of soils were studied: composition, microstructure, physical properties (bulk density, dry density, particle density, porosity and degree of water saturation), physical-chemical properties (plasticity index, relative swelling, volumetric shrinkage, soil soaking, cationic exchange capacity, $\mathrm{pH}$ factor), deformation (hydro-consolidation characteristics: coefficient of relative subsidence ability), and strength parameters (cohesion, internal friction angle). By water, muriatic and alkaline extracts, the components and structural bonds such as water soluble salts, carbonates, amorphous sesqui-oxides, silicon earthy and mobile $\mathrm{Al}_{2} \mathrm{O}_{3}$ forms were determined. The granulometric analysis was done by the pipette method, using three processes of specimen preparation: (1) aggregate process (shaking up of the specimen in water causes destruction of water-unstable aggregates); (2) semi-disperse process (boiling of triturated specimen in the presence of ammonia), and (3) disperse preparation (boiling of triturated specimen with sodium pyrophosphate caused the maximum destruction of aggregates). The data of the semi-dispersed samples were used to determine soil texture class. For all fractions the micro-aggregation coefficient was calculated (Larionov 1971; Ryashchenko et al. 2000) which showed the difference of fraction contents, determined by disperse and aggregate methods of specimen preparation.

For granulometric microstructure analysis, the aggregate amounts were calculated by the methodology proposed by Ryashchenko (Ryashchenko et al. 2000, 2008); also the elementary coefficient and the type of ground structural model were estimated by Ryashchenko's methodology (Ryashchenko 2010). Using this methodology, the type of ground structural model was determinated by the size of dominant (prevailing) structural elements and their elementarity coefficient. Elementarity coefficient of structural elements of ground $G_{i}$ presents a part (percent content) of nonaggregate (free) particles $M_{i}$ in the total amount of all structural elements of the ground $\left(\mathrm{X}_{\mathrm{i}}\right)$.

\section{Results and discussion}

\subsection{Analysis of basic process determining factors}

\subsubsection{Level and climate factors}

For investigation of the water level and climate factors, the data from the Balagansk weather station (weather station: 306120 , latitude: $54^{\circ} \mathrm{N}$; longitude: $103.33^{\circ} \mathrm{E}$; altitude: $427 \mathrm{~m}$ a.s.l., Russian Federation) were used.

Atmospheric precipitation is one of the determining factors for landslide process behaviour (rates and amounts of sliding soil mass); this is because of dual effect: (1) changing of the slope character, i.e., decrease of its strength due to soaking, swelling and deconsolidation of soil; (2) change of the stress state in the rocks of the landslide body (creation of hydrostatic and hydrodynamical water pressure (Ivanov and Trzhtsinsky 2001)). A study of heavy rainfall and snowmelt runoff periods enabled to analyze the amount and character of atmospheric precipitation as the gully forming factor (table 1) (figure 2). Yearly monitoring of the study areas typically started in early July. All recorded changes occurred during the period between July and June of the next year. The total daily precipitation amount for the investigation periods is presented in figure 3 .

The level regime of Bratsk reservoir is one of the main factors that influence the groundwater dynamics in the backwater zone, as well as the geological and geomorphological processes in the surrounding area. The amplitude of level variations, rates of level rise and lowering, duration of high or low level stands, as well as the annual and multi-year variation trends are the determining parameters of this influence (Ovchinnikov et al. 1999).

The level regime controls the retainment of slide masses on the shoal. The abrasion process in the shores during high water periods disturbs its equilibrium condition and induces reactivation of the slope soil displacement. The undercut of the gully mouth areas which reached the level of the in-shore shoals also stimulates vertical erosion and increase of the erosion forms volume. 
Table 1. Characteristics of the heavy rainfall runoff period.

\begin{tabular}{|c|c|c|c|c|c|}
\hline \multirow[b]{2}{*}{ Period } & \multirow{2}{*}{$\begin{array}{l}\text { Precipitation } \\
\text { amount }(\mathrm{mm})\end{array}$} & \multicolumn{3}{|c|}{$\begin{array}{l}\text { Number of days of heavy rainfall runoff } \\
\text { with precipitation amounts exceeding }\end{array}$} & \multirow{2}{*}{$\begin{array}{l}\text { Maximum precipitation } \\
\text { intensity }(\mathrm{mm} / \mathrm{min})\end{array}$} \\
\hline & & $10 \mathrm{~mm}$ & $20 \mathrm{~mm}$ & $30 \mathrm{~mm}$ & \\
\hline \multicolumn{6}{|l|}{ 2003-2004 } \\
\hline July-September & \multirow{2}{*}{412.3} & 6 & 1 & 1 & $0.01-0.21$ \\
\hline May-June & & 2 & 1 & 0 & $0.1-0.44$ \\
\hline \multicolumn{6}{|l|}{ 2004-2005 } \\
\hline July-September & \multirow[b]{2}{*}{423.7} & 7 & 2 & 1 & $0.03-0.83$ \\
\hline May-June & & 3 & 1 & 0 & $0.09-0.4$ \\
\hline \multicolumn{6}{|l|}{ 2005-2006 } \\
\hline July-September & \multirow{2}{*}{320.3} & 3 & 1 & 0 & $0.03-0.85$ \\
\hline May-June & & 3 & 2 & 1 & $0.03-0.16$ \\
\hline \multicolumn{6}{|l|}{ 2006-2007 } \\
\hline July-September & \multirow{2}{*}{512.1} & 9 & 5 & 4 & $0.02-2.10$ \\
\hline May-June & & 3 & 2 & 0 & $0.09-0.3$ \\
\hline \multicolumn{6}{|l|}{ 2007-2008 } \\
\hline July-September & \multirow{2}{*}{236.6} & 0 & 0 & 0 & $0.04-2.12$ \\
\hline May-June & & & No data & & \\
\hline
\end{tabular}

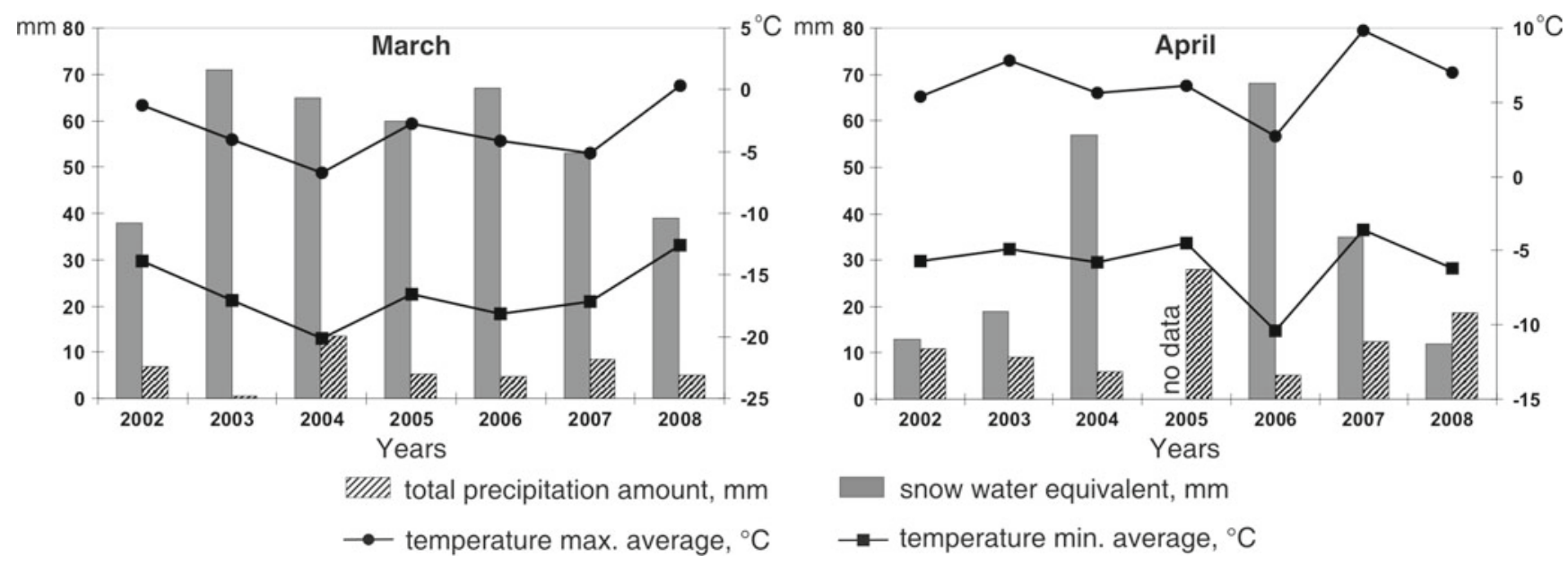

Figure 2. Characteristics of snowmelt runoff periods.

\subsubsection{Analysis of the interacting process environment}

Peculiarities of the sediment cover were studied in the areas of natural exposure of the gully slopes, landslide scars, and sliding zone. The granulometric analysis data are given in figure 4 . Peculiarities of the soil physical properties are presented in table 2 .

The vertical section of the right slope of a $3 \mathrm{~m}$ deep gully in landslide body exposed the succession of rock layers (looking from the top). The profile is represented by a $1 \mathrm{~m}$-thick layer of grain alluvial sand (samples 1-1 and 1-2) and a 2 m-thick layer of medium silty loam and light loam (samples 1-3 and 1-4).
The loam (sample 1-4) stripped at a 2.8 m-depth (the depth mark of gully thalweg) has the moisture content $\mathrm{W}=29.6 \%$, approximating to liquid limits $\mathrm{Wt}=32.8 \%$; this proves high water saturation and soft-plasticity state of the soil. In the case of supersaturation by rainwater, soil becomes fluid; the structural characteristics show low sulphate salinity (water-soluble salt contents Sws $=0.565 \%$ ), and total carbonate contents $\mathrm{Scr}=38.7 \%$.

The loams are characterized by low deformation resistance. A high degree of volumetric shrinkage $(\mathrm{U}=15.1 \%)$ proves that the dried-up loams are marked by cracking, desquamation and lamination that can disturb the continuity and strength of rock massifs. The soil is marked by low cohesion 

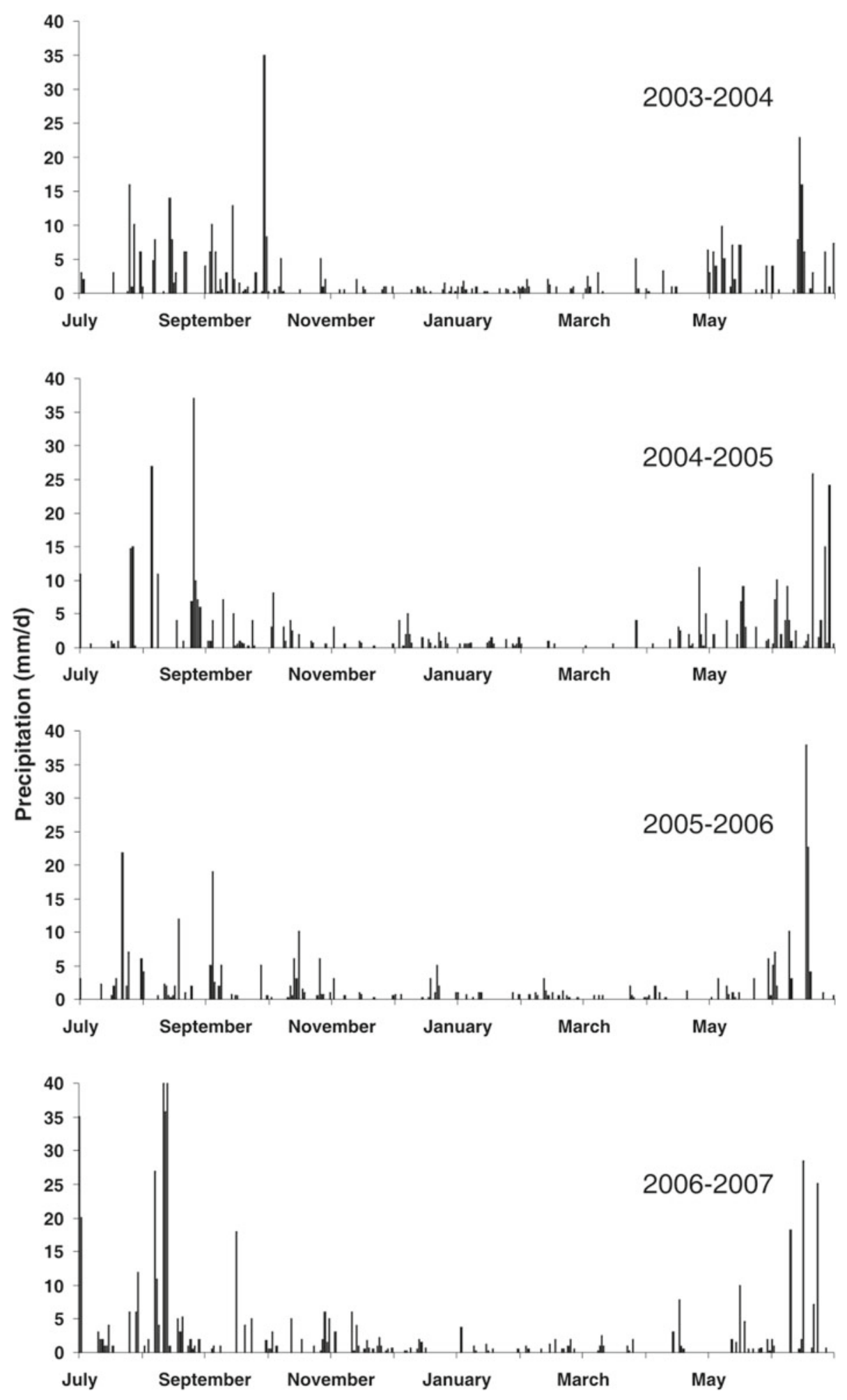

Figure 3. Total daily precipitation amount for the investigation periods.

(0.055 $\mathrm{MPa}$ at a $17^{\circ}$ angle of internal friction), lack of hydro-consolidation properties at natural pressure (coefficient of relative subsidence ability Esl 0.0021), and high soaking capacity (9 min soaking time).
Large steepness of gully slopes as well as fluidity and cracking of sand and loam layers induce the landslide process; in the thalweg gully area, a liquefaction slide develops. Abundance of runoff water in the gully bottom induces saturation of 


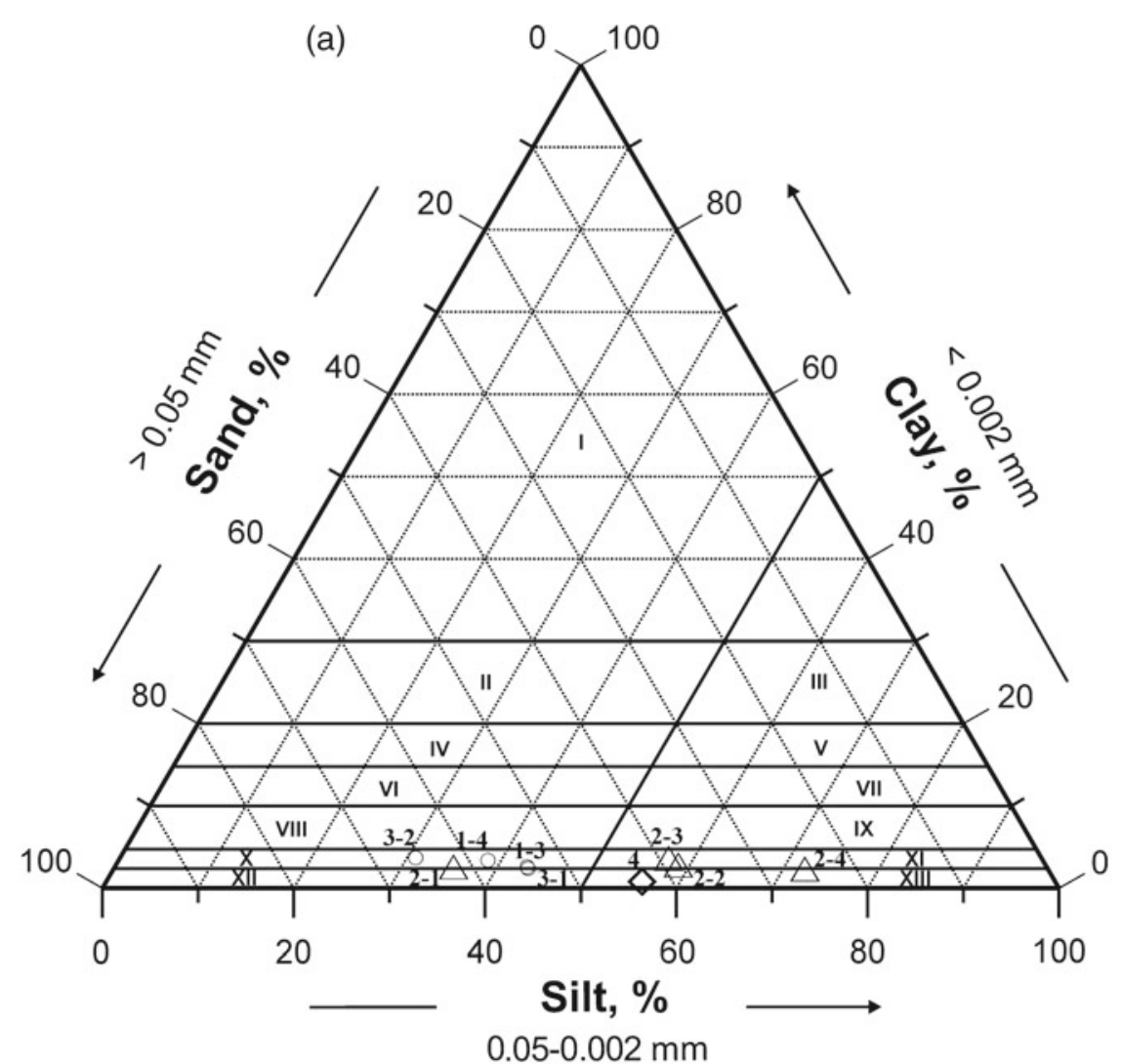

I - clay; II - heavy loam; III - silty heavy loam; IV - medium loam; V- medium silty loam; VI - light loam; VII - silty light loam; VIII - heavy sandy loam; IX - silty heavy sandy loam; $\mathrm{X}$ - light sandy loam; XI - silty light sandy loam; XII - sand; XIII - silty sand
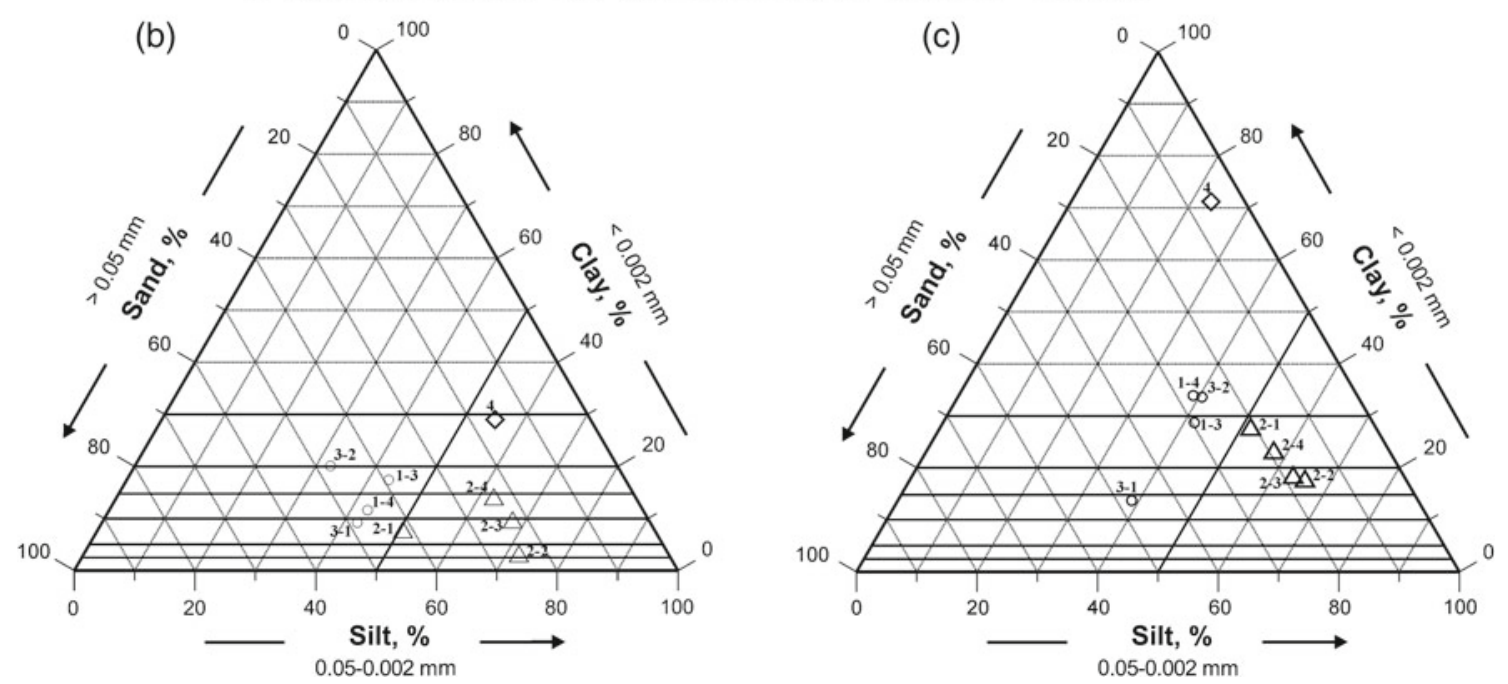

Figure 4. Texture diagram of soil composition in the site of Bykovo: (a) using pipette method with the aggregate specimen preparation; (b) using pipette method with the semi-disperse specimen preparation; and (c) using pipette method with the disperse specimen preparation (boiling with sodium pyrophosphate).

soils, lowering of their strength, and development of liquefaction slide.

Analysis of the soils sampled from the area of liquefaction slide (sample 3-1) proves presence of underconsolidated fluid heavy sandy loam layer with void ratio $\mathrm{E}=1.05 ; 22.2 \%$ moisture content and $22.5 \%$ liquid limits Wt. The texture diagram (figure 4a) shows the coincidence of samples 1-3 from the gully and 3-1 from the landslide body.

In May-June 2004, a soil sample was taken from the active slide zone; the granulometric analysis showed the presence of wet red-brown loam in the upper area of slide zone. At $1.1 \mathrm{~m}$ depth, mass of the loam is in plastic state and hard consistency; 


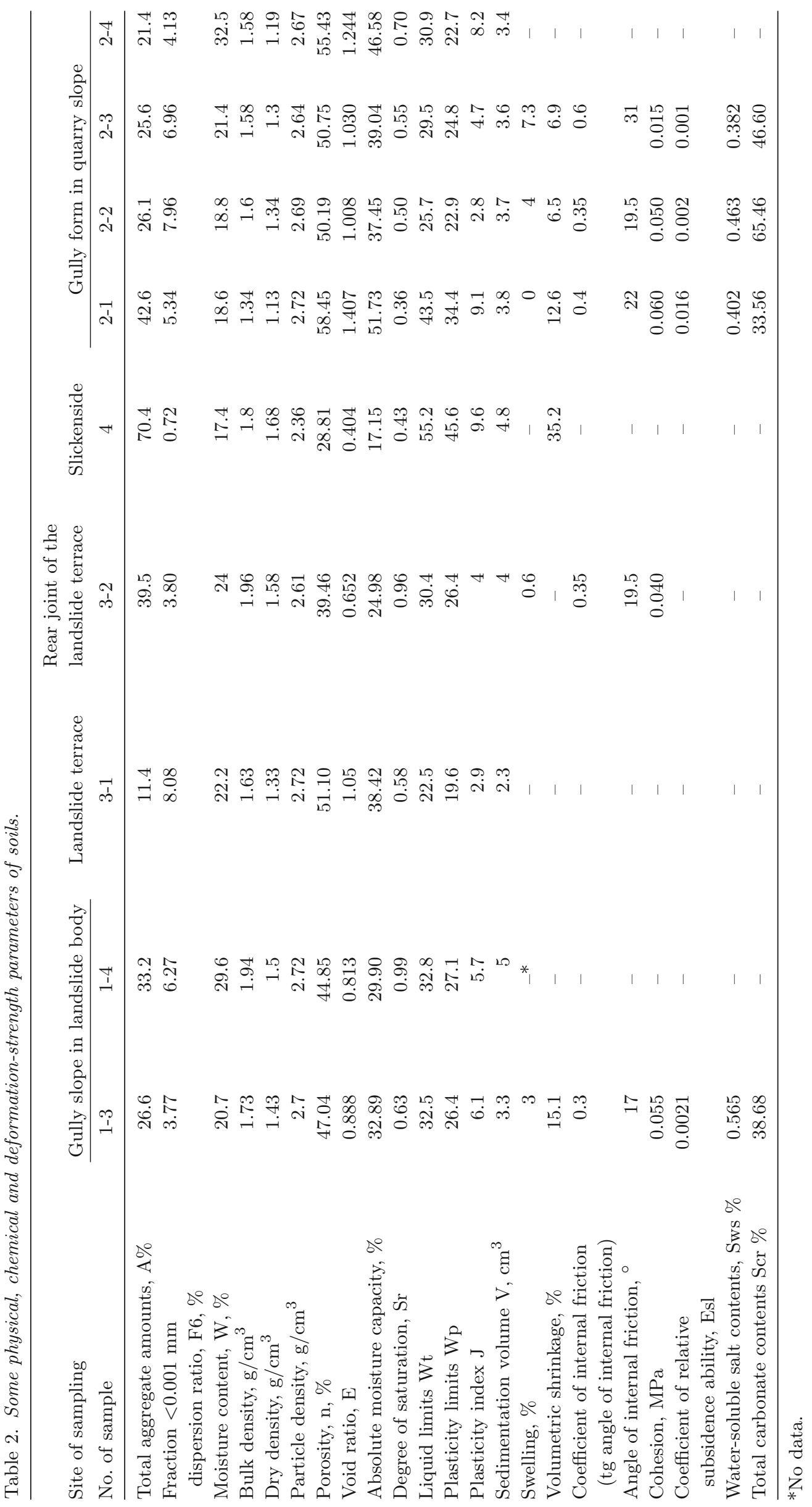


the soil sample from $3.4 \mathrm{~m}$ depth split into hard striated plates (figure 5).

Laboratory analysis of the loam from the slide zone (sample 4) revealed a high degree of aggregation in the clay fraction determined by difference in the clay fraction contents in specimen of disperse and microaggregate preparation. In the loam, domination of aggregates of fine-sandy $(0.25-0.05 \mathrm{~mm})$ and coarse silty $(0.05-0.01 \mathrm{~mm})$ fractions was recorded. By total amount of aggregates A (70.4\%), the loam structure was defined as aggregated (Makarov et al. 2000).

Occurrence of slide deformations can be attributed to the low strength properties of the soils. Loams from the slide zone are marked by low strength characteristics (0.02 $\mathrm{MPa}$ cohesion and $22^{\circ}$ angle of internal friction); in terms of sedimentation volume $\mathrm{V}=4.8 \mathrm{~cm}^{3}$, these belong to quick ground with silty-colloidal structure bonds, low swelling (1.1\%) and large volumetric shrinkage $(\mathrm{U}=35.2 \%)$. High degree of volumetric shrinkage $(35.2 \%)$ in deep layers is the cause of low strength properties of soils, contributing to origination of landslide. The data on the strength properties (cohesion and angle of internal friction) of the soil in the slide zone correspond to those published in the work of Jian et al. (2009).

Through investigation, two types of soil massif deformation were defined:

(a) Shear slide: this type of deformation is subdivided into

(1) rotational slide (soil displacement by roundcylindrical surface with small tilting), and

(2) consequent deformation (translational slide): soil displacement by sloping surface; the displacement zone of the soil massif with low physical-mechanical strength, or the place of contact of engineering-geological elements);

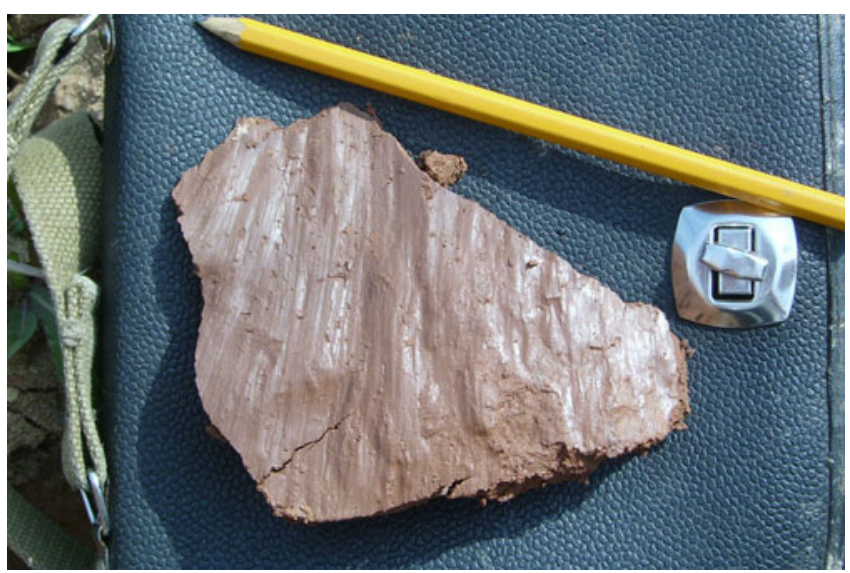

Figure 5. Sample of loam from the slide zone with a peculiar slickenside hatch.

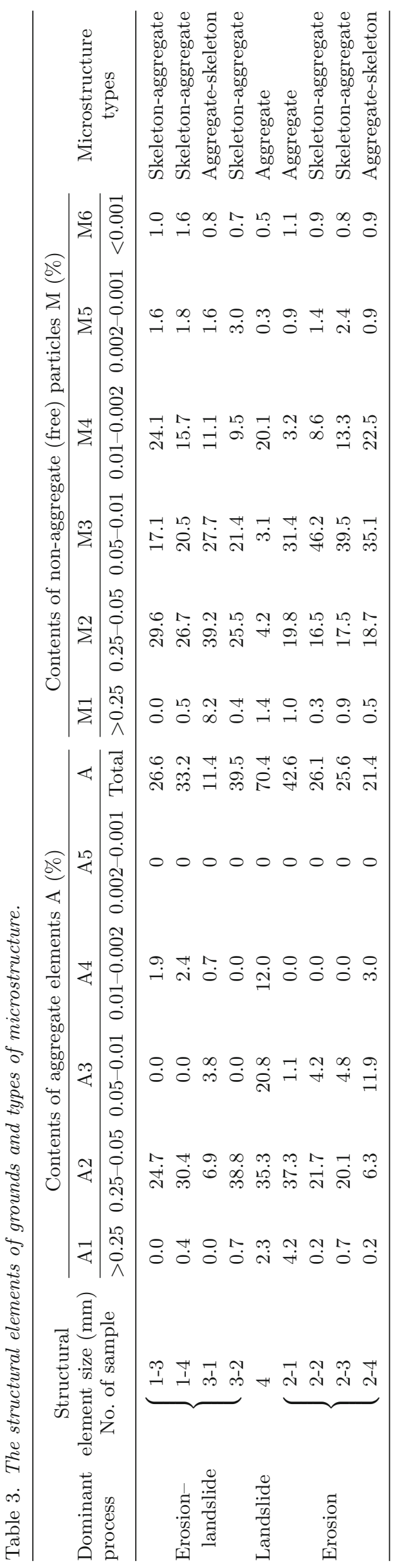


Model of erosion-landslide interaction

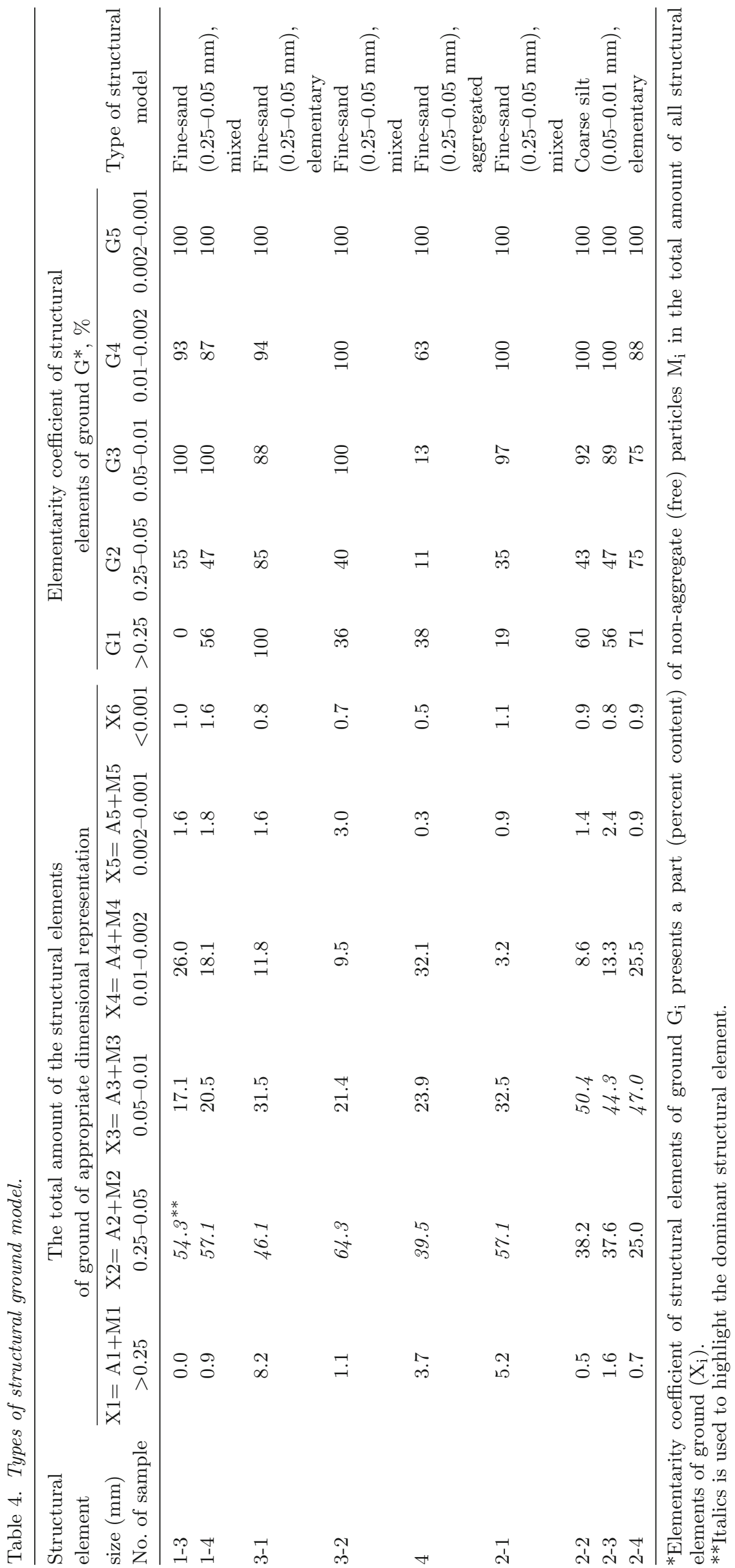


(b) Viscoplastic deformation that presents the tongue-shape massifs of liquefaction slide. In most cases, the sliding soil massifs reach the reservoir water edge.

The erosion process in quarry slopes develops in soil massifs (samples 2-1, 2-2, 2-3 and 2-4) comprised by intercalating heavy sandy loam (samples 2-1 and 2-3), and silty sand (sample 2-2) underlain by light silty loam. The granulometric composition is comprised by more silty soils (see figure $4 \mathrm{a}$ and b); non-aggregated elements are comprised primarily by coarse silty particles (0.05$0.01 \mathrm{~mm})(31.4-46.2 \%)$; the structural elements are comprised mainly by coarse silty particles (44.3-50.4\%) (table 3). The soil microstructure type is skeleton-aggregated, the type of structural model is coarse silt, elementary. The sandy loams and loams are marked by low consolidation degree (dry density $1.13-1.34 \mathrm{~g} / \mathrm{cm}^{3}$, void ratio E 1.01-1.41), humid condition (degree of saturation $\mathrm{Sr}=0.4-0.7)$, higher degree of cohesion (0.015$0.060 \mathrm{MPa}$ ), probably due to higher carbonate contents Scr $34-66 \%$, with $22^{\circ}-31^{\circ}$ angles of internal friction. Soils of this type, i.e., those of high porosity, silty microstructure and high water permeability, tend towards erosion rather than to shear slide or other plastic deformations.

Table 3 shows skeleton-aggregate microstructure typical of the soils prone to erosion-landslide processes. Here, fine-sand elements (0.25-0.05 mm) comprise majority (39.5-64.3\%); particles of similar size are prevalent also among the nonaggregated particles (25-39\%). The structural model is comprised by fine-sandy mixed and elemental (sample 3-1) particles (table 4). The exception is sample 4 from the slide zone which is marked by prevalence $(20.1 \%)$ of fine silty particles (0.010-0.002 mm) (among the non-aggregate particles). In the disperse state, the sample contained $69.9 \%$ of fine-clay $(<0.001 \mathrm{~mm})$ particles, the major part of them $(69.4 \%)$ are aggregated. The loams from slide zone are of aggregate microstructure; the structural model is of the fine-sandy character. Thus, structure of the soils prone to shear deformation is represented primarily by lowcohesion fine-sand particles and aggregates, this is proved by the soil test results: a $0.02 \mathrm{MPa}$ cohesion and a $22^{\circ}$ angle of internal friction.

The diagram (figure 4c) shows the results of granulometric analysis of disperse-prepared soil samples, where two groups can be distinguished: the soils associated with erosion-landslide mechanisms, and those associated with the mechanism of erosion.

Once again, we see that the peculiarities of composition, structure, and properties of soils of both cited groups determine different mechanisms.

\subsection{Dynamics}

\subsubsection{Period of 2003-2004}

In 2003, at low water levels the erosion processes and stabilization of slope slide deformation were recorded. In the emerge areas, abrasive scars of $0.5-1.5$ and $0.35-0.39 \mathrm{~m}$ height were intensely scored (figure 6).

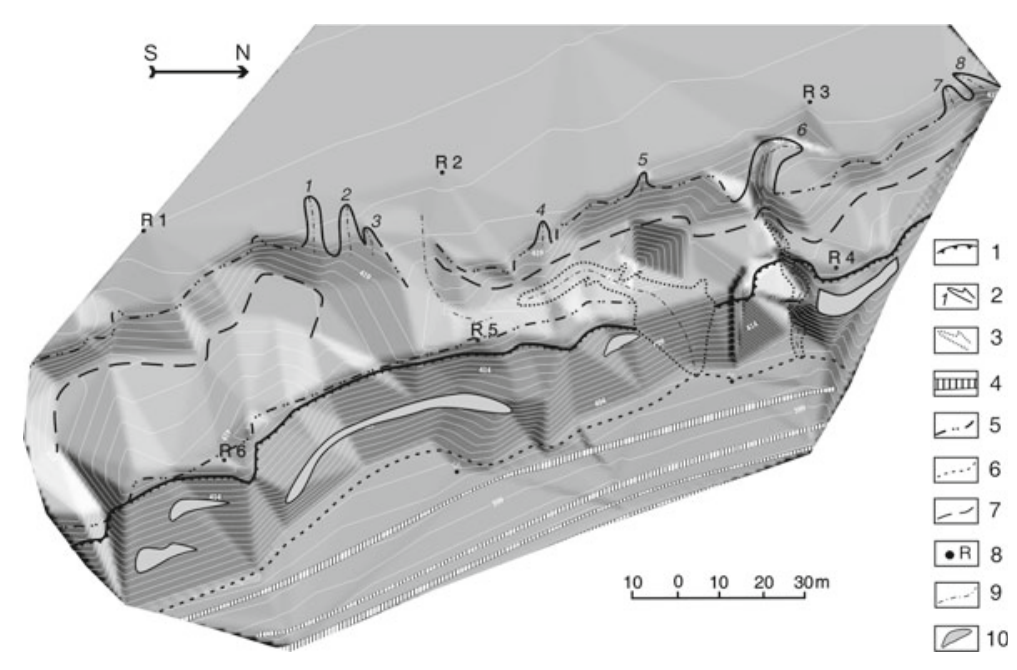

Figure 6. Cartographic model of the Bykovo site (2003). (1) Landslide scar; (2) gully developing in quarry slope; (3) gully reaching the shore zone; (4) abrasive scar; (5) border of the quarry; (6) foot of landslide slope; (7) foot of rear quarry slope; (8) bench mark; (9) gully thalweg; and (10) landslide terrace. 
During the period of May-June 2004, a $2.7 \mathrm{~m}$ rise of water level was recorded. The activation of landslide processes exceeded the rates of gully erosion. In the north area of the described site, a $3.5 \mathrm{~m}-$ high landslide scar in the $46^{\circ}$ dipping slide zone appeared (figure 7). The slid soil masses formed a sort of jam in the middle and mouth parts of gully; in the central part, the slid soil tongue reached the reservoir water edge.

After heavy rainfalls on June 30 and July 1, 2004 , the temporary aquifer originated in sand layers overtop by clay rock massifs, whose discharge on the steep slope and the gully thalweg caused the additional inundation and reactivation of liquefaction slide. Abundant water in the gully bottom decreased the soil stability that contributed to the landslide process. This was proved by laboratory tests of the studied soils (see section 5.1.2). Due to the flow slide processes, the gully increased in width and decreased in depth; this phenomenon manifested itself in the form of a small increment of the landslide deformation areas $\left(+174 \mathrm{~m}^{2}\right)$ and the erosion-affected areas $\left(+46 \mathrm{~m}^{2}\right)$ (table 5$)$. The gullies developed in the quarry slopes irrespective of the water level regime, and landslide processes were also marked by positive dynamics $\left(+10 \mathrm{~m}^{2}\right)$. This can be attributed to the abundant, but not intense, precipitation in 2003.

(a)

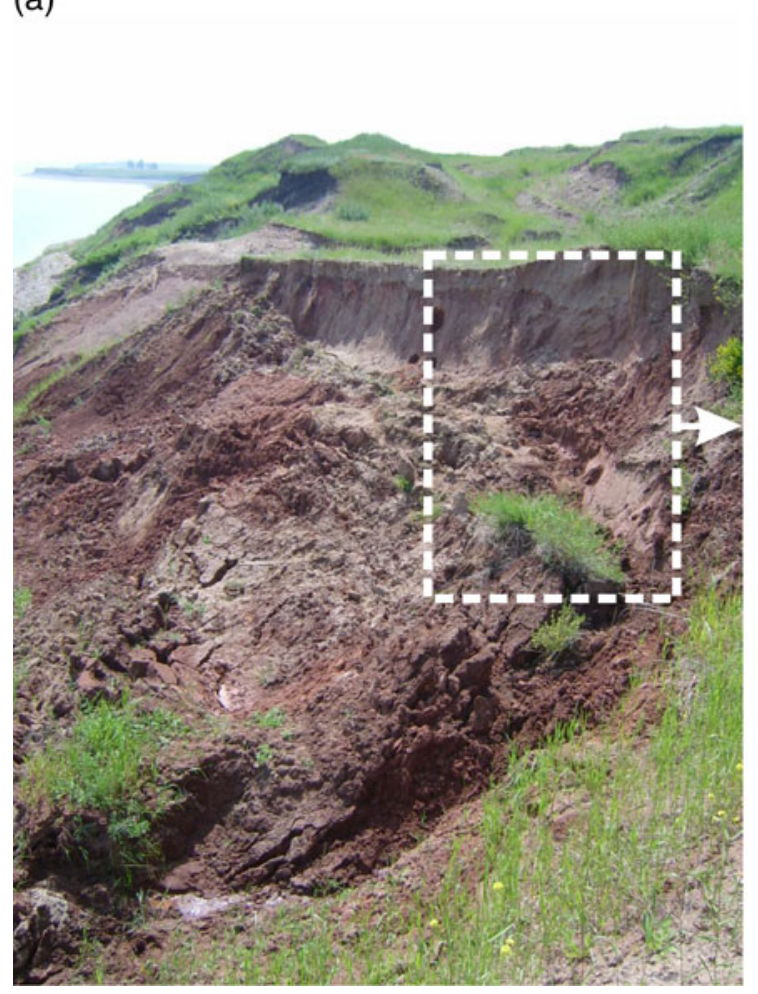

5.2.2 Period of 2004-2005

The landslide areas increased slightly $\left(151 \mathrm{~m}^{2}\right.$ increment). During the warm humid period of spring 2005, the shore was covered by slid defrosted soil mass, and hence the landslide slope foot neared the water edge for $10.5 \mathrm{~m}$.

In humid period of summer-autumn 2004, an activation of landslide process in slopes was recorded. However, the water level rise and abrasion-induced retreat of the landslide slope foot caused real decrease of the landslide displacement areas in autumn 2004. Therefore, only a small increment of the area of landslide displacement during the period of 2004-2005 was recorded.

The erosion processes were marked by maximum positive dynamics $\left(+258 \mathrm{~m}^{2}\right)$ during the whole investigation period that can be attributed to favourable climate conditions. This is typical of both groups of erosion forms.

\subsubsection{Period of 2005-2006}

During the summer-autumn period of 2005, the high water level $(399.5 \mathrm{~m})$ was the reason for abrasion and the $10-13 \mathrm{~m}$ retreat of the slope foot. This caused activation of slide processes. The maximum increment of the landslide displacement

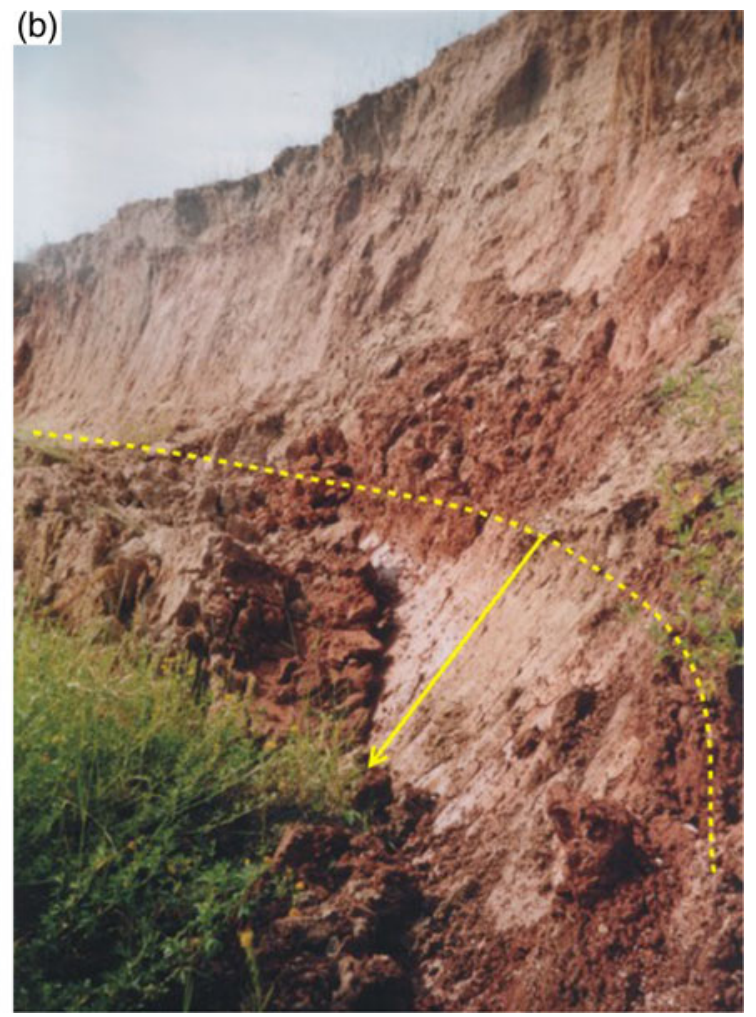

Figure 7. Small-scale (a) and large scale (b) views of active landslide deformations in the landslide scar in 2004. 


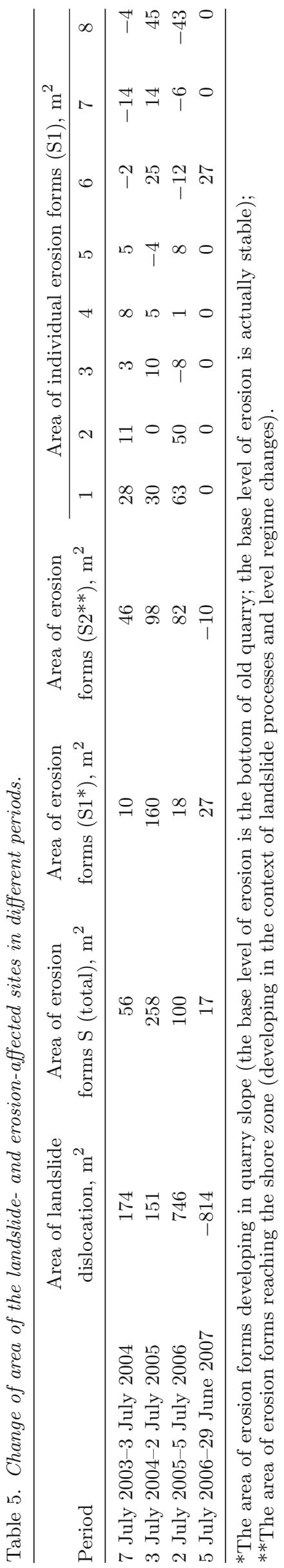

area $\left(+746 \mathrm{~m}^{2}\right)$ due to the formation of additional slide terraces was recorded. The landmarks on the beach were washed away. The intense development of erosion forms in the context of landslide process was determined by level regime $\left(+82 \mathrm{~m}^{2}\right)$, as well as the abundance of thaw water in spring 2006 (see section 5.1.1).

\subsubsection{Period of 2006-2007}

Activation of landslide process in spring 2006 was brought about by abundant atmospheric precipitation and highest water level marks (e.g., $401.2 \mathrm{~m}$ ). The upward retreat of the slope edge was evidenced by the destruction of the soil massif (crest) between the quarry and shore slope at the №. 6 benchmark. Besides, the mouth parts of several gullies were jammed by a slid soil mass. The erosion forms developing in the landslide slope caused the cumulative negative dynamics of growth of the area $\left(-10 \mathrm{~m}^{2}\right)$. For example, the negative dynamics for two particular erosion forms was $-110 \mathrm{~m}^{2}$ and $-50 \mathrm{~m}^{2}$.

The maximum decrease of the landslide area $\left(-814 \mathrm{~m}^{2}\right)$ could be explained by a 4.3 meter retreat of the slope foot due to abrasion; in July 2007 therefore, no slid soil mass could be found on the shore shoal.

It has been revealed by numerous studies that landslide activation could be triggered by rainfall events (Guzzetti et al. 2004; Macfarlane 2009; Saito et al. 2010; Li et al. 2011) as well as by reservoir inundation (Wang et al. 2008; Jian et al. 2009). However, Qi et al. (2006) suggested that the rainfall impacts on the slide deformation process substantially increased after reservoir inundation.

The study of the process dynamics enabled us to draw the following conclusions. During the period of 2003-2006, accretion of the landslide displacement area, as well as a reasonable rise of water level marks within the multi-year trend were recorded (figure 8). The maximum growth rates of the slidedislocation areas were observed during the 20052006 period, marked by abundant atmospheric precipitation and the cases of sharp water level rise up to the high level marks (e.g., $399.3 \mathrm{~m}$ ). The results of our studies were corroborated by investigations in the area of Baishuihe landslide (Li et al. 2010), which showed that the slide dislocations were affected by the combined effects of rainfalls and water level fluctuations. Unlike the case of landslide investigated by $\mathrm{Li}$ et al. (2010) who reported an increase of slide deformations, particularly after water level drawdown, our investigations revealed an increase of slide deformation extents as the consequence of the cases of high water level stand. This occurs due to decrease of 


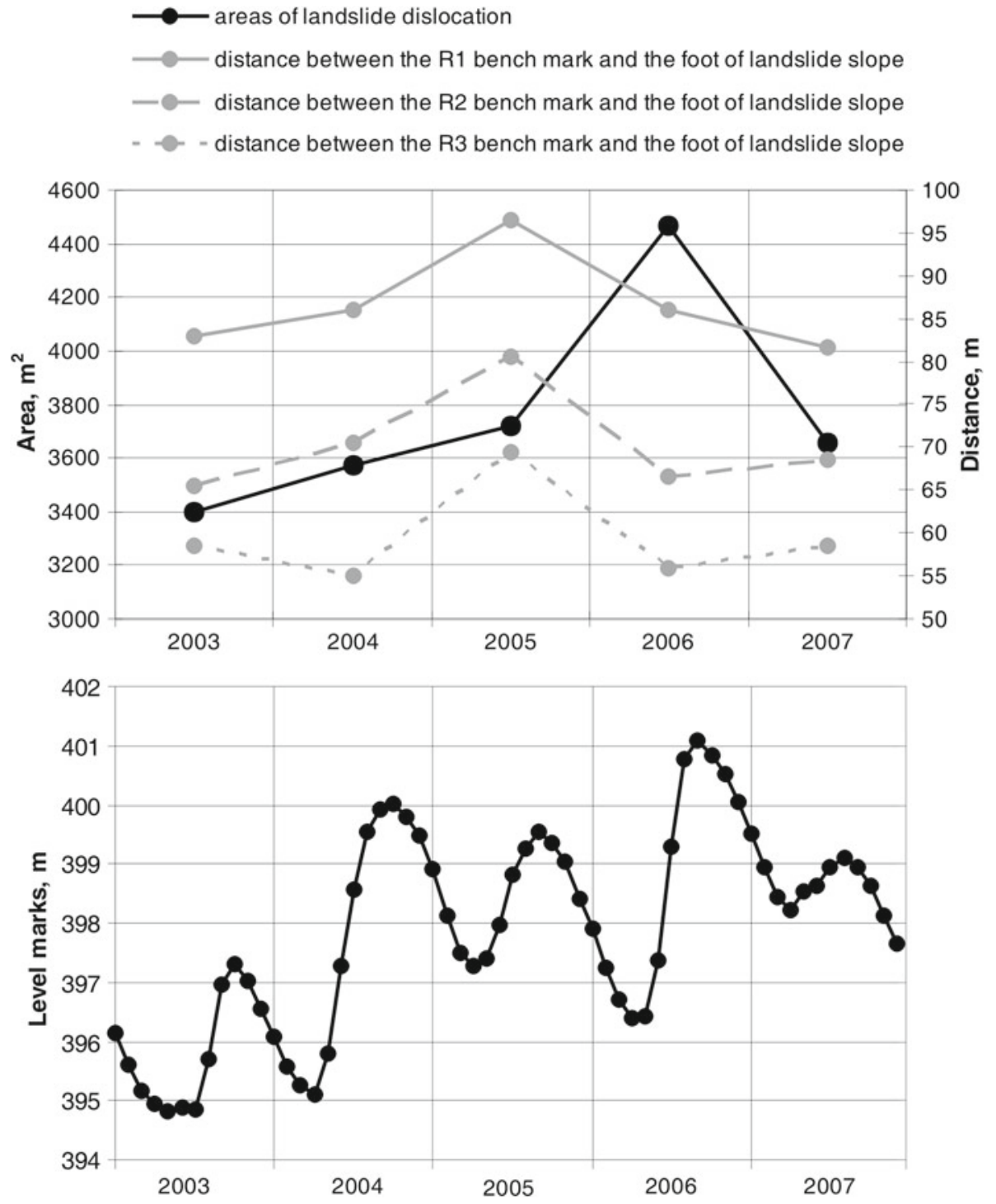

Figure 8. The dynamics of landslide dislocation and abrasive retreat of slope foot in the context of the reservoir water level variation.

strength properties of rocks by inundation (the rise of groundwater level, abundant atmospheric precipitation), and abrasional undermining of shore slopes (disturbance of slope stability).

During the 2006-2007 period, a substantial decrease of slide deformation extents was observed. The intense abrasion accompanied by the retreat of slide slope foot was recorded in all bench marks since 2005. The reservoir water level almost reached the normal backwater level marks that impeded the detection of landslide reactivation and the increase of landslide extents.

\subsection{Mechanisms (model) of erosion-landslide relationship at different water level stands}

The analysis of the described factors, process environment and dynamics enabled to create a two-stage descriptive model of erosion-landslide relationships in the context of water level variations in the Bratsk reservoir. The model represents the consequence of relationships in local geo-systems at changing level marks.

Stage 1: High water level in the reservoir stimulates activation of landslide process. Under these conditions, the process of abrasion of shore slopes, formation of wave-cut notches and recession of slope foot cause a decrease of stability in the steep shore slopes. The excessive water saturation of soil attributed to both the climate (abundant atmospheric precipitation) and hydrodynamical factors (the reservoir water level rise followed by a rise of groundwater level) leads to deconsolidation and decrease of the soil strength properties. Loose material filling various karst landforms (caves, cavities, hollows) and containing minerals 
of montmorillonite in the clay fraction forms a sliding zone. Jian et al. (2009) also reported that minerals in the slip zones of the Anlesi landslide (Three Gorges reservoir, China) are mainly composed of montmorillonite. This implies that this material is marked by swelling capacity and low shear strength properties. During the dry period, the volumetric shrinkage of soils leads to cracking, sheeting and disintegration of rocks and decrease of soil massif stability. All these factors stimulate the activation of landslide processes that occur in the form of origination of landslide terraces, the upslope displacement of the existing landslide scar, slide of fluid soil on the inshore shoal (i.e., the factors that influence dynamics of the areal changes), or in the increasing landslide terrace number, development of secondary deformations inside the landslide body, origination of new fractures (these kinds of process occurrence do not influence the quantitative indices of areal dynamics).

The intensity of landslide processes stimulates the changes of morphology in shore slopes. Development of liquefaction slide processes in gully slopes leads to increase of gully width and decrease of gully depth, as well as to jamming of mouth parts of erosion forms.

Stage 2: During the low water periods, the activation of erosion and stabilization of landslide processes in shore slopes can be observed. The disturbance of longitudinal equilibrium due to abrasion of shore benches and gully mouth parts stimulates the vertical erosion. High energy of shore scarp erosion contributes to the transport of large amounts of soil on the shoal area. Gradual lowering of the water level stimulates the formation of secondary abrasion scarps and alluvial cones which are subject to scouring by erosion.

Lowering of the reservoir water level followed by the groundwater level lowering induces the intensive ground water runoff within the shore massif and activation of karst-suffusion-subsidence processes, that also benefit the increase of erosion forms.

The dynamics and relationships of shore processes are marked by definite cyclic recurrence according to the reservoir level regime, i.e., the alternating periods of high and low water stands. The discussed processes are marked by relative stabilization - until the recurrent water level change.

\section{Summary}

On the basis of investigation results, the following conclusions should be made:

- More complicated geodynamical situations are formed by a combination of processes rather than by any particular process. The criterion of geodynamical trends in local geosystems is determined by the level regime of the Bratsk reservoir.

- Landslide and erosion processes are antagonistic to each other within local shore geosystems, their joint action, however, increases the effect of shore slope transformation.

- The activation of landslide processes in the reservoir shores follows the periods of high water level stands. The disturbance of shore slope stability is induced by abrasion of slope foot and inundation of the slide zone.

- Due to liquefaction slide in gully slopes stimulated by abundant precipitation, the gully forms increase considerably in width and decrease in depth.

- Soils subject to landslide, erosion and erosionlandslide processes differ in microstructure properties. Largest erosion susceptibility is typical of soils with skeleton-aggregated microstructure, fine- and coarse-silt sandy loams and loams of high porosity, whose interstructural bonds are attributed to water-soluble salts (Sws $=0.4-$ $0.5 \%)$ and high carbonate contents $\left(\mathrm{Scr}=34^{-}\right.$ $66 \%)$.

- The loams of the slide zone feature high dispersion and aggregation of clay fractions are typical. The structure of the soils subject to landslide deformation is comprised primarily by fine-sand particles and aggregates with smaller cohesion and shear strength properties.

- Abrasion of shore slopes disturbs the longitudinal profile of erosion forms, whose mouth parts reach the inshore shoal areas. The lowering of the reservoir water level stimulates the development of vertical erosion; intensive suffusion-subsidence processes induce the linear growth of gully forms.

\section{References}

Bazhenova O I, Lyubtsova E M, Ryzhov Yu V and Makarov S A 1997 Spatio-temporal analysis of the dynamics of erosion processes in the south of Eastern Siberia; Nauka, Novosibirsk (in Russian).

Bondarik G K 1981 The general theory of engineering (physical) geology; Nedra, Moscow.

Brundsen D and Thornes J B 1979 Landscape sensitivity and change; Trans. Inst. Brit. Georg. 4 463-484.

Cornforth D H 2005 Landslides in practice: Investigation and remedial/preventive options in soils; Wiley, New Jersey.

Fiorillo F 2003 Geological features and landslide mechanisms of an unstable coastal slope (Petacciato, Italy); Eng. Geol. $67255-267$.

Guzzetti F, Cardinali M, Reichenbach P, Cipolla F, Sebastiani C, Galli M and Salvati P 2004 Landslides triggered by the 23 November 2000 rainfall event in the Imperia Province, Western Liguria, Italy; Eng. Geol. 73 229-245.

Harvey A M 2001 Coupling between hillslopes and channels in upland fluvial systems: Implications for landscape 
sensitivity, illustrated from the Howgill Fells, northwest England; Catena 42 225-250.

Harvey A M 2002 Effective timescales of coupling within fluvial systems; Geomorphology 44 175-201.

Hervas J (eds) 2003 Lessons learnt from landslide disasters in Europe; Report EUR 20558 EN, European Communities, Ispra.

Isika N S, Doyuranb V and Ulusays R 2004 Assessment of a coastal landslide subjected to building loads at Sinop, Black Sea, Turkey, and stabilization measures; Eng. Geol. 75 69-88.

Ivanov I P and Trzhtsinsky Yu B 2001 Engineering geodynamics; Nauka, St. Petersburg (in Russian).

Jian W, Wang Zh and Yin K 2009 Mechanism of the Anlesi landslide in the Three Gorges Reservoir, China; Eng. Geol. 108 86-95.

Khak V A and Kozyreva E A 2012 Changes of geological environment due to the anthropogenic impacts: A case study of south of East Siberia, Russia; Z. Geomorphol. 56 183-199.

Krut I V 1973 The study bases of theoretical geology; Nauka, Moscow (in Russian).

Larionov S A 1971 Methods of investigation of soil structure; Nedra, Moscow (in Russian).

Li C, Ma T, Zhu X and Li W 2011 The power-law relationship between landslide occurrence and rainfall level; Geomorphology 130 221-229.

Li D, Yin K and Leo Ch 2010 Analysis of Baishuihe landslide influenced by the effects of reservoir water and rainfall; Environ. Earth Sci. 60 677-687.

Lomtadze V D 1977 Engineering geology. Engineering geodynamics; Nedra, Leningrad (in Russian).

Macfarlane D F 2009 Observations and predictions of the behaviour of large, slow-moving landslides in schist, Clyde Dam reservoir, New Zealand; Eng. Geol. 109 5-15.

Makarov S A, Ryashchenko T G and Akulova V V 2000 Geo-ecological analysis of territories marked by development of natural-technogenic processes in NeogeneQuaternary deposits of Pribaikalia; Nauka, Novosibirsk (in Russian).

Mazaeva O A, Kozyreva E A and Trzhtsinskii Yu B 2006 Assessing the interaction of exogenous processes in the local coastal geosystems of the Bratsk reservoir; Geography and Natural Resources 3 81-86 (in Russian).

Ovchinnikov G I, Pavlov S C and Trzhtsinsky U B 1999 Change of geological environment in the zones of influence of the Angara-Yenisei reservoirs; Nauka, Novosibirsk (in Russian).

Palshin G B (ed.) 1968 Engineering geology of Pribaikalia; Moscow, Nauka (in Russian).
Pinyol N M, Alonso E E, Corominas J and Moya J 2012 Canelles landslide: Modelling rapid drawdown and fast potential sliding; Landslides $933-51$.

Qi S, Yan F, Wang S and Xu R 2006 Characteristics, mechanism and development tendency of deformation of Maoping landslide after commission of Geheyan reservoir on the Qingjiang River, Hubei Province, China; Eng. Geol. 86 37-51.

Ryashchenko T G 2010 Regional soil science (Eastern Siberia); IEC SB RAS, Irkutsk (in Russian).

Ryashchenko T G, Akulova V V and Erbaeva M A 2008 Loessial soils of Priangaria, Transbaikalia, Mongolia, and northwestern China; Quat. Int. 179 90-95.

Ryashchenko T G, Akulova V V, Grigorieva I Yu, Ruwe D, Zhengzhong Zh and Chongshao S 2000 Analysis of microstructure of loesses of the Northern Loess Plateau, China; Geoecology, Engineering Geology, Hydrogeology, Geocryology 3 234-240 (in Russian).

Saito H, Nakayama D and Matsuyama H 2010 Relationship between the initiation of a shallow landslide and rainfall intensity - duration thresholds in Japan; Geomorphology 118 167-175.

Schwab M, Rieke-Zapp D, Schneider H, Liniger $M$ and Scjlunegger F 2008 Landsliding and sediment flux in the Central Swiss Alps: A photogrammetric study of the Schimbrig landslide, Entlebuch; Geomorphology 97 392-406.

Slattery M C, Gares P A and Phillips J D 2002 Slopechannel linkage and sediment delivery on North Carolina coastal plain cropland; Earth Surf. Proc. Land. 27 1377-1387.

Trzhtsinskii Yu B 1978 Landslides along the Angara reservoirs; Bull. Int. Assoc. Eng. Geol. Environ. 17 42-43.

Trzhtsinsky Yu B, Pavlov S Kh and Kozyreva E A 2003 The landslides in karstic rock massifs of Upper Priangaria; Geography and Natural Resources 1 87-93 (in Russian).

Valentin C, Poesen J and Li Y 2005 Gully erosion: Impacts, factors and control; Catena 63 132-153.

Wang F, Zhang Y, Huo Z, Peng Xu, Wang Sh and Yamasaki Sh 2008 Mechanism for the rapid motion of the Qianjiangping landslide during reactivation by the first impoundment of the Three Gorges Dam reservoir, China; Landslides 5 379-386.

Yudin E G 1978 System approach and principles of activity; Nauka, Moscow (in Russian).

Zinck J A, Lopez J, Metternichtj G I, Shresthal D P and Vazques-Selem L 2001 Mapping and modeling mass movements and gullies in mountainous areas using remote sensing and GIS techniques; Int. J. Appl. Earth. Obs. 3 $43-53$. 